\title{
New Public Management and the Educational Executives' Selection Policies in Greece
}

\author{
V.P. Andrikopoulos ${ }^{1}$ and A. A. Ifanti ${ }^{2}$ \\ ${ }^{1,2}$ Laboratory of Sociology and Education, Department of Educational Sciences and Early Childhood \\ Education, University of Patras, Greece
}

\begin{abstract}
This study attempts to explore the selection policies of the educational executives, i.e.: Directors and Regional Directors of Primary and Secondary Education, in Greece, in the 1981-2020 period, and their impact of New Public Management.

New Public Management approach has influenced public administration and policy in several countries around the globe, inevitably affecting the operation of schools and other educational organizations. Therefore, several changes have been enacted, in an attempt to challenge the status quo of the bureaucratically organized educational institutions. In this way, Greece seems to be abided by the international trends and to adopt specific elements ascribed to the New Public Management approach, giving impetus to educational administration being transformed.

For the purpose of this study, primary and secondary sources were examined, i.e.: institutional and legislative texts issued by the Greek Department of Education, in the period under consideration, as well as the relevant literature on the topic. Data analysis revealed that during the first decades the selection policies and practices for the educational executives' post have constantly focused on the teaching experience as the main asset for the candidate teachers. However, the advent of the millennium seems to coincide with a shift in educational administration, in that the selection criteria are enriched, and the teaching experience ceases to be the main selection factor. New issues appear to gain ground, i.e.: the scientific knowledge and the managerial skills along with teachers' academic qualifications, professional development and their lifelong learning experiences. In this way, the Greek state seems to follow the international trends and to adopt specific elements ascribed to the New Public Management approach.
\end{abstract}

Summing up, this case study reveals the challenges that the New Public Management model appears to have on the educational administration in Greece, giving rise to other studies in this field.

Keywords: New Public Management, Educational Executives, selection policies, Greece 